\title{
Perianal mass in a female transgenic mouse
}

\author{
Katherine A. Naff, DVM, Carolyn Van Pelt, PhD, DVM, DACVP, Suzanne \\ Craig, DVM, DACLAM \& Kenneth Gray, DVM, MS, DACLAM
}

\begin{abstract}
A 9-month-old primiparous mouse, a retired breeder from a colony of transgenic adenocarcinoma of the mouse prostate (TRAMP) mice, was examined for perianal swelling (Fig. 1). The mouse had never undergone any experimental manipulations.
\end{abstract}

All animals in the TRAMP colony were group-housed in microisolator cages on flat-shelf racks and maintained in specific pathogen-free conditions. The mice had ad libitum access to a standard autoclaved laboratory mouse diet and autoclaved reverse osmosis-treated water. The microbiological status of the colony, as determined by quarterly sentinel testing, was negative for 12 viral pathogens and for endoparasites and ectoparasites.

The mouse was euthanized via $\mathrm{CO}_{2}$ narcosis. On necropsy, we observed a firm, raised perianal mass (Fig. 1). The mass was excised and submitted for histopathologic examination; we observed no other gross abnormalities.

What is the most likely histologic diagnosis of the perianal mass? What is the most likely tissue of origin of the perianal mass? Do you think the perianal mass is a

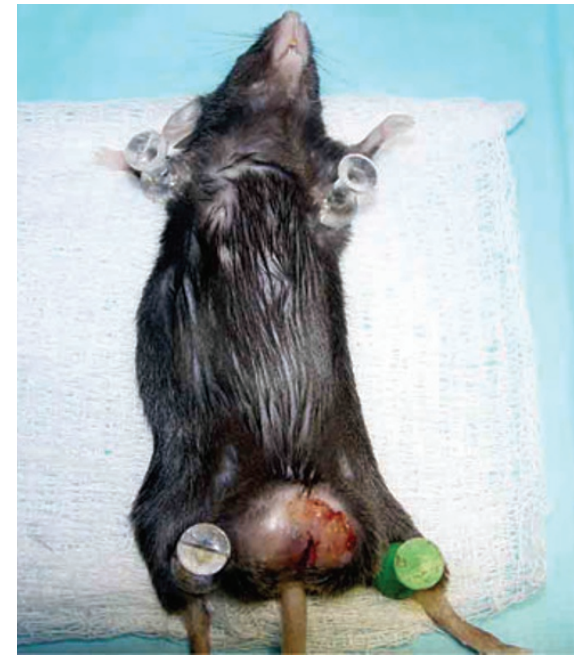

FIGURE 1 | A euthanized 9-month-old, retired breeder female TRAMP mouse with a firm, raised perianal mass.

tumor? If it is a tumor, could tumorigenesis be associated with expression of the transgene? How would you then prove or disprove your hypothesis?

\section{What's your diagnosis?}

LAB ANIMAL welcomes reader contributions to "What's Your Diagnosis" in case history/ diagnosis format. Submissions should include two to five illustrations or photos. Please email manuscripts to editors@labanimal.com. Selections are made on the basis of relevance and interest to readers. Please refer to the Guide to Authors for information on submission of digital figures.

Department of Veterinary Medicine and Surgery, The University of Texas M.D. Anderson Cancer Center, Unit 63, 1515 Holcombe Blvd., Houston, TX 77030. Correspondence should be addressed to K.A.N. (kanaff@mdanderson.org). 